\title{
5-Hydroxymethylcytosine in the mammalian zygote is linked with epigenetic reprogramming
}

\author{
Mark Wossidlo', Toshinobu Nakamura², Konstantin Lepikhov', C. Joana Marques ${ }^{3}$, \\ Valeri Zakhartchenko ${ }^{4}$, Michele Boiani ${ }^{5}$, Julia Arand ${ }^{1}$, Toru Nakano², Wolf Reik ${ }^{3,6} \&$ Jörn Walter ${ }^{1}$
}

The epigenomes of early mammalian embryos are extensively reprogrammed to acquire a totipotent developmental potential. A major initial event in this reprogramming is the active loss/demethylation of 5-methylcytosine $(5 \mathrm{mC})$ in the zygote. Here, we report on findings that link this active demethylation to molecular mechanisms. We detect 5-hydroxymethylcytosine $(5 \mathrm{hmC})$ as a novel modification in mouse, bovine and rabbit zygotes. On zygotic development $5 \mathrm{hmC}$ accumulates in the paternal pronucleus along with a reduction of $5 \mathrm{mC}$. A knockdown of the $5 \mathrm{hmC}$ generating dioxygenase Tet3 simultaneously affects the patterns of $5 \mathrm{hmC}$ and $5 \mathrm{mC}$ in the paternal pronucleus. This finding links the loss of $5 \mathrm{mC}$ to its conversion into $5 \mathrm{hmC}$. The maternal pronucleus seems to be largely protected against this mechanism by PGC7/ Dppa3/Stella, as in PGC7 knockout zygotes $5 \mathrm{mC}$ also becomes accessible to oxidation into $5 \mathrm{hmC}$. In summary, our data suggest an important role of $5 \mathrm{hmC}$ and Tet3 for DNA methylation reprogramming processes in the mammalian zygote.

\footnotetext{
${ }^{1}$ Department of Genetics/Epigenetics, Saarland University, Saarbrücken 66123, Germany. ${ }^{2}$ Department of Stem Cell Pathology, Medical School and Graduate School of Frontier Biosciences, Osaka University, 1-3 Yamadaoka, Suita, Osaka 565-0871, Japan. ${ }^{3}$ Laboratory of Developmental Genetics and Imprinting, The Babraham Institute, Cambridge CB22 3AT, UK. ${ }^{4}$ Department of Molecular Animal Breeding and Biotechnology, Ludwig-Maximilian University, Munich 81377, Germany. ${ }^{5}$ Max-Planck-Institut für molekulare Biomedizin, Röntgenstraße 20, Münster 48149, Germany. ${ }^{6}$ Centre for Trophoblast Research, University of Cambridge, Cambridge, CB2 3EG, UK. Correspondence and requests for materials should be addressed to J.W. (email: j.walter@mx.uni-saarland.de).
} 
G enome-wide reprogramming of DNA methylation (5-methylcytosine; $5 \mathrm{mC})$ is an important epigenomic process observed in mammalian primordial germ cells and early embryos. The reprogramming of DNA methylation has a direct influence on genomic imprints, the regulation of pluripotency and stem cell networks, the erasure of epimutations and the transcriptional control of transposons ${ }^{1-3}$. In the mammalian zygote, the $5 \mathrm{mC}$ content of the paternal chromosomes is substantially reduced before replication of DNA, as detected by immunofluorescence (IF) imaging with antibodies against $5 \mathrm{mC}^{4-7}$. Several lines of evidence suggest that the conversion of $5 \mathrm{mC}$ to cytosine can be induced by deamination followed by DNA glycosylase-induced base excision repair ${ }^{8-10}$. We recently analysed the dynamics of active loss/demethylation of $5 \mathrm{mC}$ using bisulphite sequencing on staged mouse zygotes. We could indeed find a potential link between $5 \mathrm{mC}$ demethylation and base excision repair. In addition, we reported that the loss of $5 \mathrm{mC}$ is less pronounced compared with the extensive signal reduction observed by IF with antibodies against $5 \mathrm{mC}^{7}$. The latter observation prompted us to search for additional mechanisms that may contribute to the zygotic loss of $5 \mathrm{mC}$. The recent detection of 5-hydroxymethylcytosine $(5 \mathrm{hmC})$ in Purkinje and embryonic stem (ES) cells, strongly suggests that this modification could indeed have an intermediate function in reprogramming of $5 \mathrm{mC}^{11,12}$. The extensive conversion of $5 \mathrm{mC}$ into $5 \mathrm{hmC}$ in the zygote would explain the rapid loss of $5 \mathrm{mC}$ IF signal, while at the same stages we see a remarkable maintenance of modifications at cytosines using sodium bisulphite sequencing. Note that both modifications, $5 \mathrm{mC}$ and $5 \mathrm{hmC}$, are resistant to bisulphite induced deamination and thus cannot be discriminated in bisulphite sequencing reactions ${ }^{13}$. The presence of $5 \mathrm{hmC}$ has not been examined in zygotes. $5 \mathrm{hmC}$ can be formed by hydroxylation of $5 \mathrm{mC}$ by the dioxygenases Tet1, Tet 2 and Tet3. Tet1 expression was reported in the zygote and a knockdown of Tet1 during early embryogenesis revealed effects on inner cell mass specification ${ }^{14}$.

In this paper, we describe a detailed analysis of $5 \mathrm{hmC}$ distribution in mouse and other mammalian zygotes, as well as in cloned embryos. We also analysed the effect of Tet1-3 ablation and the absence of the protective factor PGC7 on the dynamics of 5hmC and $5 \mathrm{mC}$ in the maternal and paternal pronuclei of the developing mouse zygote. Our findings point towards a major role of $5 \mathrm{hmC}$ in the process of epigenetic reprogramming during the earliest phase of development and open new perspectives on the mechanisms of active DNA demethylation.

\section{Results}

Dynamic appearance of $5 \mathrm{hmC}$ during zygotic development. We first investigated the presence of $5 \mathrm{hmC}$ using several polyclonal and monoclonal antibodies raised and tested against $5 \mathrm{hmC}$ (see Methods for details). All antibodies show a strong reactivity in advanced mouse zygotes (Fig. 1a; Supplementary Fig. S1). 5hmC signals are most prominent in the paternal pronucleus, in which the reactivity against $5 \mathrm{mC}$ antibody is already weak. The opposite patterns are found in the maternal pronucleus. Here, strong staining by the $5 \mathrm{mC}$ antibody is accompanied by a much less intense $5 \mathrm{hmC}$ signal. The $5 \mathrm{mC}$ content of the paternal pronucleus is known to dynamically change over the first cell cycle. We followed the dynamics of $5 \mathrm{hmC}$ in comparison to $5 \mathrm{mC}$ patterns across all pronuclear stages of the zygote (see Fig. $1 \mathrm{~b}$ for an example of $5 \mathrm{hmC}$ ). The relative changes within the paternal and maternal pronuclei, respectively, were determined by image quantification using standardized fixation, denaturation and imaging conditions (Fig. 1c-f). At the earliest developmental stages after sperm entry (PN0 and PN1) both compact pronuclei show 5hmC and $5 \mathrm{mC}$ signals of similar intensities. On further development the distribution, intensities and ratios of $5 \mathrm{hmC}$ and $5 \mathrm{mC}$ signals become increasingly different for maternal and paternal pronuclei, respectively, towards the end of the first cell cycle (Fig. 1b-f and Supplementary Fig. S2). The $5 \mathrm{hmC}$ signal steadily increases in the paternal pronucleus by about sevenfold at late PN3 (beginning of $\mathrm{S}$-phase), whereas the $5 \mathrm{mC}$ signal decreases. Similar, but much less pronounced changes are detectable in the maternal pronucleus. Here, the $5 \mathrm{hmC}$ signal increases moderately (about twofold at PN3), whereas the $5 \mathrm{mC}$ signal decreases slightly. This decrease of the maternal $5 \mathrm{mC}$ content has not been documented before; it only becomes evident when quantifying the relative $5 \mathrm{mC}$ intensities normalized against DNA antibody signals.

Both pronuclei not only differ in the signal intensities, but also the distribution of $5 \mathrm{hmC}$ signals up to late S-phase. Although $5 \mathrm{hmC}$ stains the paternal genome across the entire pronucleus, the signal in the maternal one is concentrated in heterochromatic rings around nucleolar precursor bodies. During S-phase the paternal $5 \mathrm{hmC}$ content remains about threefold higher than the maternal one (Fig. 1d). In G2-phase (PN5), the 5hmC signals reach their maximum in both pronuclei (Fig. 1c). At metaphase, the arms of the paternal chromosomes are strongly stained for $5 \mathrm{hmC}$ in contrast to maternal chromosomes, on which the $5 \mathrm{mC}$ signal predominates. An exception is the pericentromeric regions, which on both maternal and paternal chromosomes retain a strong $5 \mathrm{mC}$ signal (Fig. 1a). This indicates that parental chromosomes not only differ in the quantity, but also in the relative distribution of $5 \mathrm{mC}$ and $5 \mathrm{hmC}$. The parental differences in $5 \mathrm{hmC}$ apparently persist into the 2-cell stage. Here, nuclear regions with a stronger $5 \mathrm{hmC}$ stain most likely demarcate the territory of still separated paternal chromatin (see Fig. 1b). The image processing of nuclei of late 2-cell embryos (in G2-phase), which have completed the second round of replication, reveal that 2-cell embryos retain approximately the same $5 \mathrm{hmC}$ signal intensities as PN5 pronuclei (G2-phase) of the zygote. Thus, unlike in the first cell cycle, the $5 \mathrm{hmC}$ content is not further altered (neither increased nor decreased) during G1 and S-phase of 2-cell embryos. In line with this, we observe a strong decrease of Tet3 expression in 2-cell embryos (see below).

Accumulation of $5 \mathrm{hmC}$ is independent of DNA replication. In the paternal pronucleus, $5 \mathrm{hmC}$ begins to accumulate at early to mid PN3, that is, before replication commences. The strongest increase, however, is detectable during S- and G2-phase. This led us to investigate, whether the appearance of $5 \mathrm{hmC}$ is dependent on DNA replication. Zygotes incubated with aphidicolin from late G1-phase onwards do not replicate their DNA (no EdU or BrdU incorporation, see also Wossidlo et al., ${ }^{7}$ Fig. 3). However, the drug does not inhibit DNA decondensation and pronuclear progression to PN5 morphology (Supplementary Fig. S3). In aphidicolin-treated late stage zygotes, $5 \mathrm{hmC}$ intensities and their pronuclear distribution are not changed compared with control mock-treated zygotes (Supplementary Fig. S3). We conclude that the accumulation of $5 \mathrm{hmC}$ occurs independently of DNA replication.

Antibody independent analysis of the presence of $5 \mathrm{hmC}$ in zygotes. To obtain independent experimental proof for the presence and dynamics of $5 \mathrm{hmC}$ in zygotes, we developed a nuclease-based in situ assay using the nuclease McrBC. McrBC was originally described to preferentially cut $5 \mathrm{hmC}$ containing DNA in comparison to $5 \mathrm{mC}^{15}$ (see also Supplementary Fig. S4a). Following McrBC in situ digestion the DNA ends are marked by TUNEL (terminal deoxynucleotidyl transferase dUTP nick-end labelling, modified HELMET assay ${ }^{16}$, see Supplementary Methods). McrBC TUNEL label increased in developing paternal pronuclei compared with maternal ones, whereas TUNEL signals were equal for both at early PN2 stages (see Supplementary Fig. S4b,d for quantification). Hence, the relative changes and dynamics in $5 \mathrm{hmC}$ observed by IF could be recapitulated by an independent assay (see also Supplementary Fig. S1). 

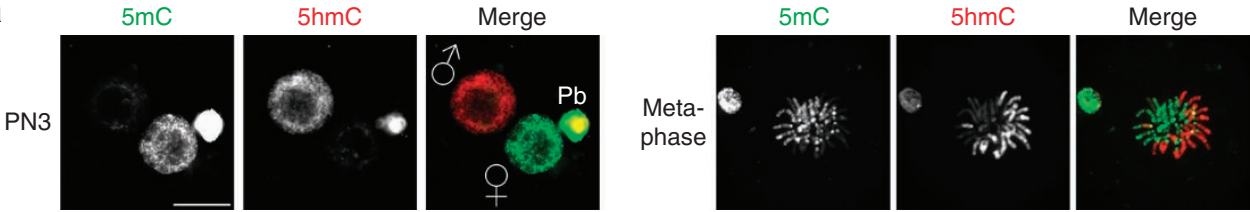

b
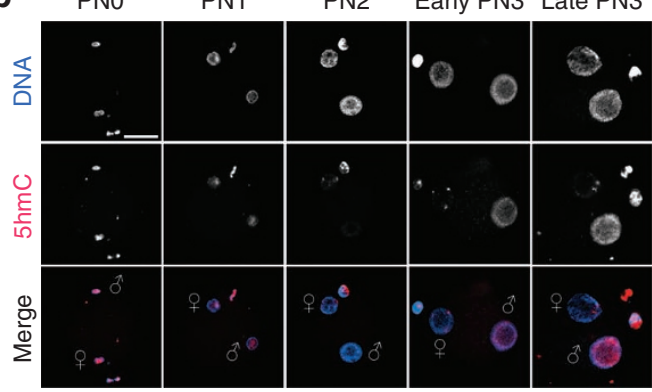

C
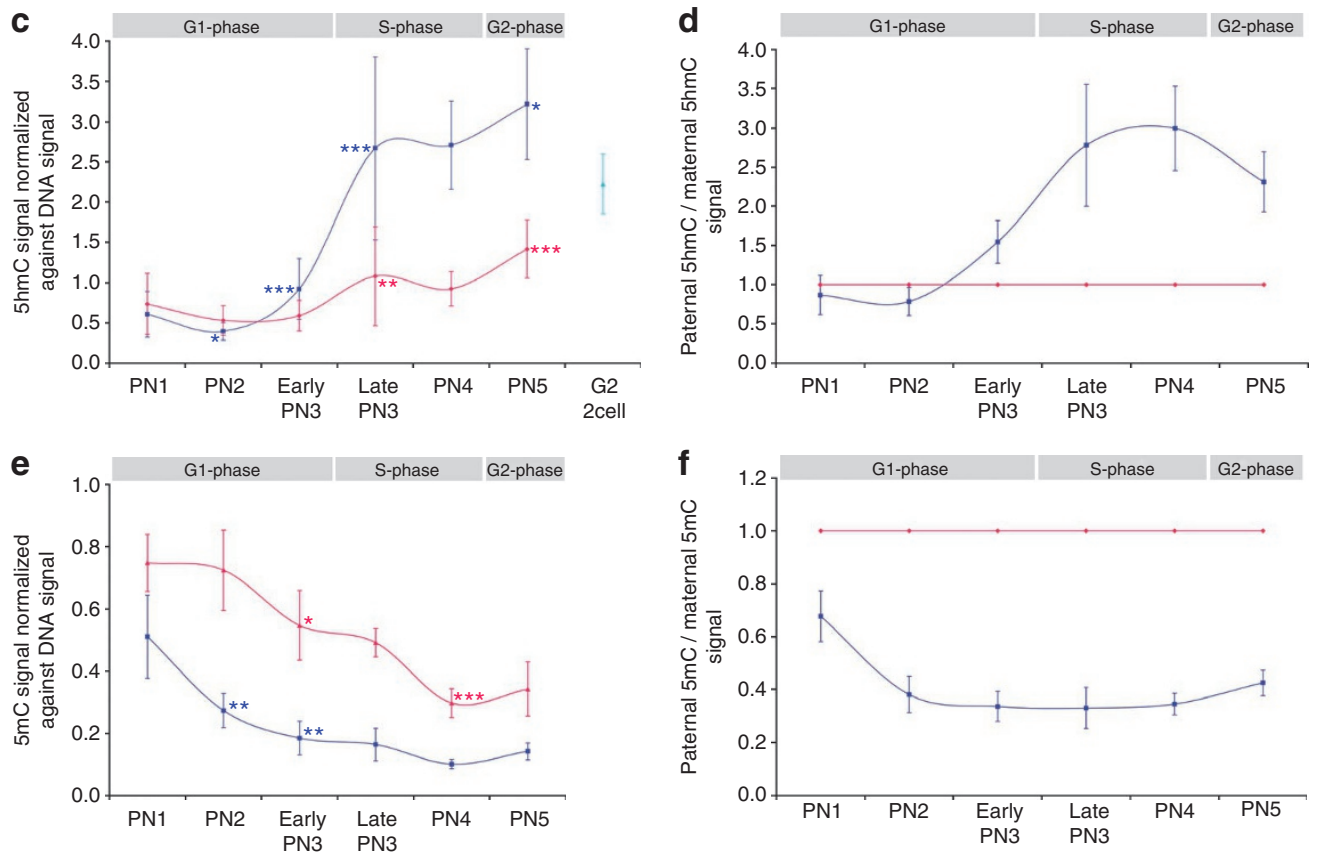

Figure 1 | $5 \mathrm{hmC}$ preferentially appears in the paternal genome of early mouse preimplantation embryos. (a) Representative images of mid PN3 and metaphase stage zygotes stained with 5-methylcytosine ( $5 \mathrm{mC}$, green mouse monoclonal, gift from Dirk Schübeler) and 5-hydroxymethylcytosine ( $5 \mathrm{hmC}$, red rabbit polyclonal from Active Motif) antibodies. (b) Dynamic appearance of $5 \mathrm{hmC}$ during early preimplantation development. Shown are representative images of embryos stained with DNA (blue mouse monoclonal from Millipore) and 5hmC (red rabbit polyclonal from Active Motif) antibodies. (c) Quantification of $5 \mathrm{hmC}$ signal normalized against DNA antibody signal. A total of 12-18 precisely staged embryos per pronuclear stage from 3 to 5 in vitro fertilization (IVF) experiments were analysed. (d) Comparison of paternal and maternal 5hmC signal (maternal signal set to 1) normalized against DNA antibody signal. (e) Quantification of $5 \mathrm{mC}$ signal normalized against DNA antibody signal. A total of 3-9 precisely staged embryos per pronuclear stage from 2 to 3 IVF experiments were analysed. (f) Comparison of paternal and maternal $5 \mathrm{mC}$ signal (maternal signal set to 1) normalized against DNA antibody signal. Asterisks show significant changes of paternal or maternal $5 \mathrm{hmC} / 5 \mathrm{mC}$ signals calculated using Student's $t$-tests $\left({ }^{\star}=P<0.05,{ }^{\star \star}=<0.01,{ }^{\star \star \star}=P<0.001\right)$. Error bars represent standard deviations. Blue line, paternal; red line, maternal signal; $\widehat{\alpha}$, male; $q$, female pronucleus; Pb, polar body; scale bar, $20 \mu \mathrm{m}$.

$5 \mathrm{hmC}$ is present in rabbit and bovine zygotes. Following our observations in mouse, we also examined the presence of $5 \mathrm{hmC}$ in rabbit and bovine zygotes, that is, two other mammals reported to show paternal DNA demethylation (see Supplementary Fig. S5 and refs. 5,17). In both bovine and rabbit zygotes, we find a similar inverse $5 \mathrm{mC}$ and $5 \mathrm{hmC}$ staining in the paternal and maternal pronuclei, respectively (Fig. 2 and Supplementary Fig. S5). We conclude that the asymmetric $5 \mathrm{hmC}$ presence is conserved in three mammalian species pointing towards a conserved role of $5 \mathrm{hmC}$ in epigenetic reprogramming.

$5 \mathrm{hmC}$ in embryos derived by somatic cell nuclear transfer. We next examined the dynamics of $5 \mathrm{hmC}$ in chromosomes of one-cell embryos obtained after somatic cell nuclear transfer (SCNT). Cloned one-cell embryos (with cumulus cells as donors) were stained for $5 \mathrm{mC}$ and $5 \mathrm{hmC}$ at 2, 6 and $12 \mathrm{~h}$ post-activation (hpa; Fig. 3). At $2 \mathrm{hpa}$ strong distinct foci of both $5 \mathrm{mC}$ and $5 \mathrm{hmC}$ are present in the two pseudo-pronuclei formed after cumulus cell nuclear transfer. Note that the remaining two spindles in the enucleated oocyte lead to the formation of these two pseudo-pronuclei. Also note that cumulus cells apparently contain a substantial amount of $5 \mathrm{hmC}$. As in zygotes, the $5 \mathrm{hmC}$ signal decreases during the first few hours of development of the cloned embryos (up to $6 \mathrm{hpa}$, late G1-phase) and is followed by an S-phase associated increase reaching high levels at $12 \mathrm{hpa}$ (that is, at early G2-phase). Conversely, the $5 \mathrm{mC}$ 

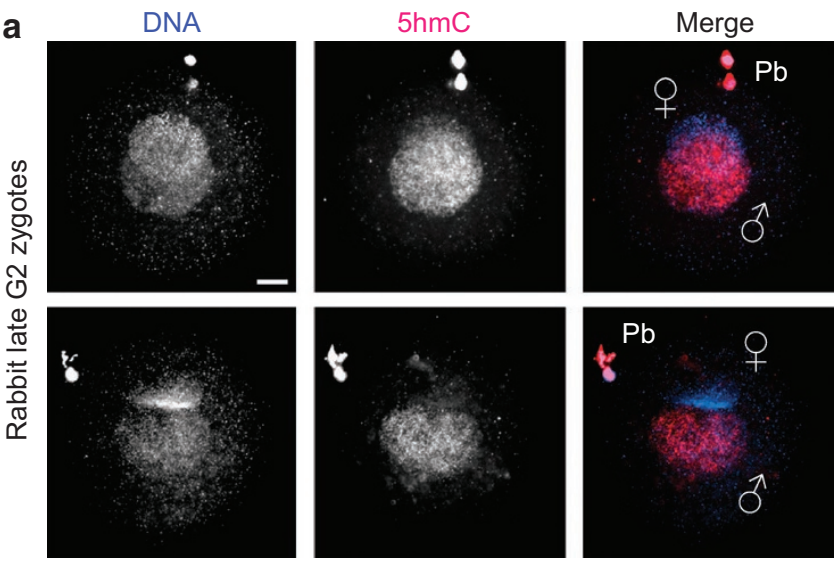

b

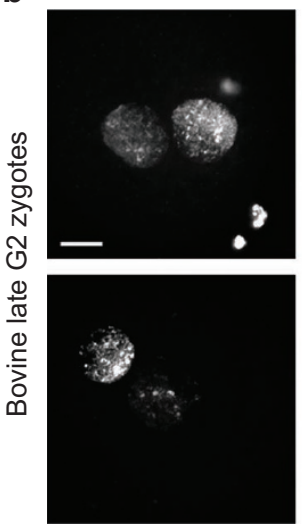

$5 \mathrm{hmC}$
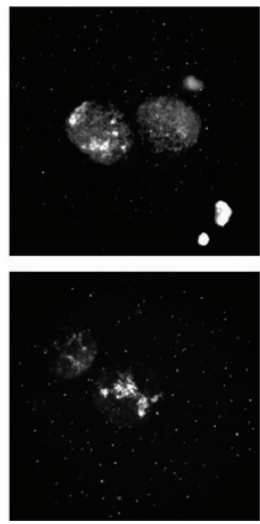

Merge
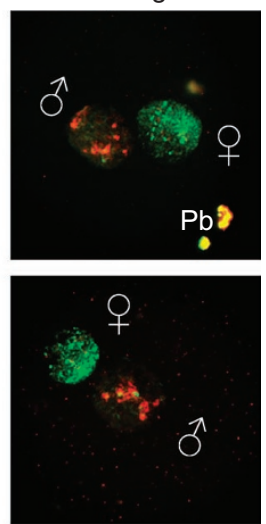

Figure $\mathbf{2}$ | $5 \mathrm{hmC}$ is present in rabbit and bovine zygotes. Representative images of (a) rabbit and (b) bovine G2-phase zygotes stained with $5 \mathrm{hmC}$ (red rabbit polyclonal from Active Motif) and DNA (blue mouse monoclonal from Millipore)/5mC (green mouse monoclonal, gift from Dirk Schübeler) antibodies $(N>10)$. 0 , male pronucleus; + , female pronucleus; $\mathrm{Pb}$, polar body; scale bar, $20 \mu \mathrm{m}$.

signal decreases during development of SCNT embryos (Fig. 3 and see refs. 5,7). The accumulation of $5 \mathrm{hmC}$ in nuclei of SCNT one-cell embryos not only confirms the modification processes that occur in zygotes derived by in vitro fertilization (IVF), but also suggests that an enzymatic activity required for the formation of $5 \mathrm{hmC}$ is provided by the oocyte cytoplasm.

Expression levels of Tet proteins in oocytes and embryos. The most parsimonious explanation for the generation of $5 \mathrm{hmC}$ in the zygote is that it is produced by the hydroxylation of $5 \mathrm{mC}$ by the Tet enzymes ${ }^{12,14}$. $5 \mathrm{hmC}$, however, can in theory also be generated independently of $5 \mathrm{mC}^{18}$. We investigated the potential involvement of the Tet enzymes in this process. Quantitative reverse transcription PCR (qRT-PCR) revealed that transcripts for Tet1, 2 and 3 are differentially expressed in oocytes, zygotes and 2-cell embryos (Fig. 4). Whereas Tet1 expression can barely be detected in oocytes and zygotes ${ }^{14}$ and Tet 2 is only moderately expressed, Tet 3 shows extremely high levels of expression confined to oocytes and zygotes, but is nearly absent at the 2-cell stage. Hence, enzymes that are potentially responsible for the dynamic generation of $5 \mathrm{hmC}$ are present in the zygote/oocyte.

RNA interference knockdown of Tet proteins diminishes loss of $5 \mathrm{mC}$. Using an RNA interference-based strategy similar to the one described by Okada et al. ${ }^{19}$ we ablated Tet $1-3$ by injecting short interfering RNAs (siRNAs) against Tet mRNAs into MII oocytes followed by intracytoplasmic sperm injection fertilization (Fig. 5a).

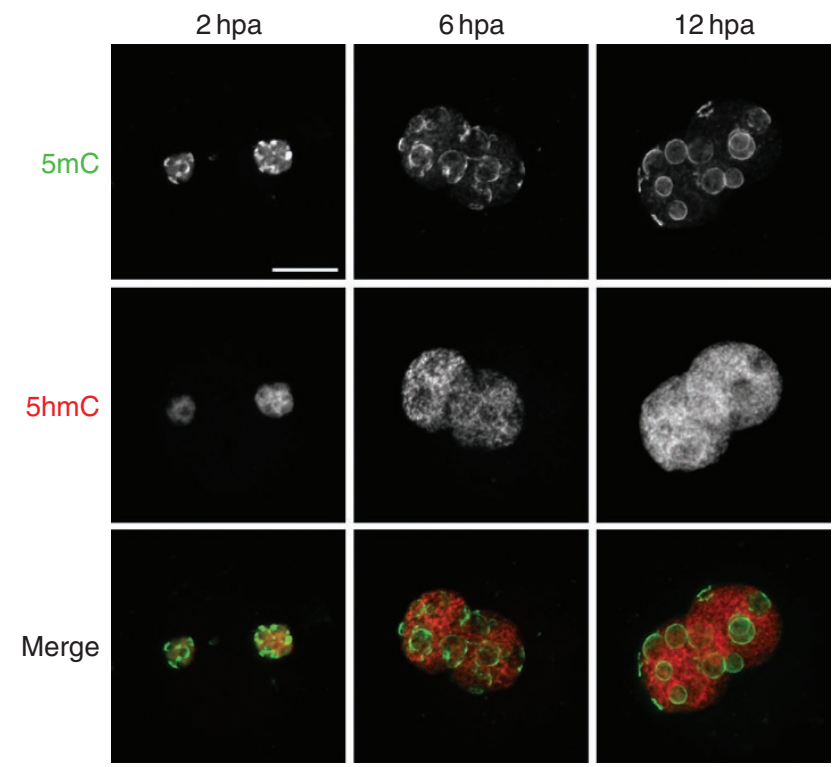

Figure $3 \mid 5 \mathrm{hmC}$ in somatic cell nuclear transfer (SCNT) derived onecell embryos. Representative images of 2,6 and $12 \mathrm{~h}$ post-activation (hpa; early G1-, late G1- and early G2-phase, see ref. 7) SCNT derived one-cell embryos stained with $5 \mathrm{mC}$ (green mouse monoclonal, gift from Dirk Schübeler) and $5 \mathrm{hmC}$ (red rabbit monoclonal from Active Motif) antibodies $(N>35)$. Scale bar, $20 \mu \mathrm{m}$.

Scrambled siRNAs with the same base composition were used as controls. 5hmC IF staining of zygotes fixed at G2-phase after injection of siRNAs against all three Tet proteins revealed a substantial reduction of $5 \mathrm{hmC}$ signals in both parental pronuclei compared with the control group (Fig. 5b-d). Consistent with the almost exclusive expression of Tet 3 in the zygote, injection of Tet3 siRNAs alone yielded similar results. We conclude that Tet 3 contributes significantly to the generation of $5 \mathrm{hmC}$ in the mammalian zygote. Most strikingly, both Tet $1-3$ and Tet 3 siRNA injections also affect the presence $5 \mathrm{mC}$ signals in the paternal pronucleus (Fig. 5e, f). In the paternal pronucleus, the $5 \mathrm{mC}$ content is strongly increased compared with control samples. This finding directly links the loss of $5 \mathrm{mC}$ signals to the conversion of $5 \mathrm{mC}$ into $5 \mathrm{hmC}$. In zygotes injected with Tet 3 siRNA this mechanism is disturbed. In contrast to the dramatic changes in the paternal pronucleus, the Tet knockdowns had only a mild and insignificant effect on the $5 \mathrm{mC}$ signal in the maternal pronucleus (Fig. $5 \mathrm{~d}$ ). We conclude that the vast majority of $5 \mathrm{mC}$ in the maternal pronucleus is inaccessible for Tet3-mediated oxidation.

PGC7 protects the maternal genome against hydroxylation. The maintenance of $5 \mathrm{mC}$ in the maternal pronucleus was shown to depend on the 'demethylation' protecting factor PGC7/Dppa3/Stella ${ }^{20}$. To test, whether generation of $5 \mathrm{hmC}$ is also influenced by PGC7, we examined the presence of $5 \mathrm{hmC}$ in the maternal pronucleus of mouse zygotes with a maternal null allele for PGC7 (Fig. 6). Indeed, in the absence of PGC7 the maternal 5hmC signal increases substantially, whereas the $5 \mathrm{mC}$ signal decreases simultaneously. This finding suggests that PGC7 shields the $5 \mathrm{mC}$ from the Tet3-mediated oxidation.

\section{Discussion}

Our results reveal an important role of $5 \mathrm{hmC}$ in genome-wide DNA methylation reprogramming. First and most importantly, we detect $5 \mathrm{hmC}$ as a highly abundant modification in the paternal pronucleus of mammalian zygotes. The presence and the parental asymmetry found in the three species point towards an evolutionary conserved role of this modification in DNA methylation reprogramming. The accumulation of $5 \mathrm{hmC}$ during the first cell cycle does apparently 
a

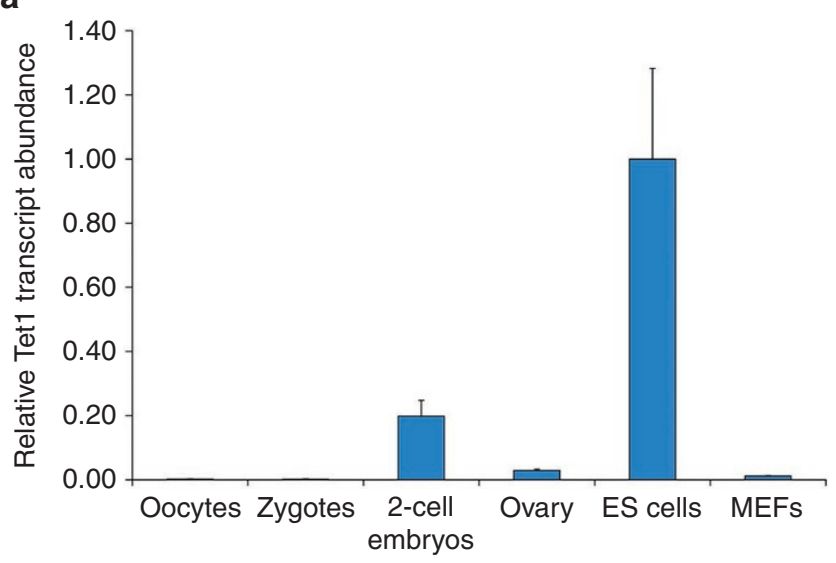

b

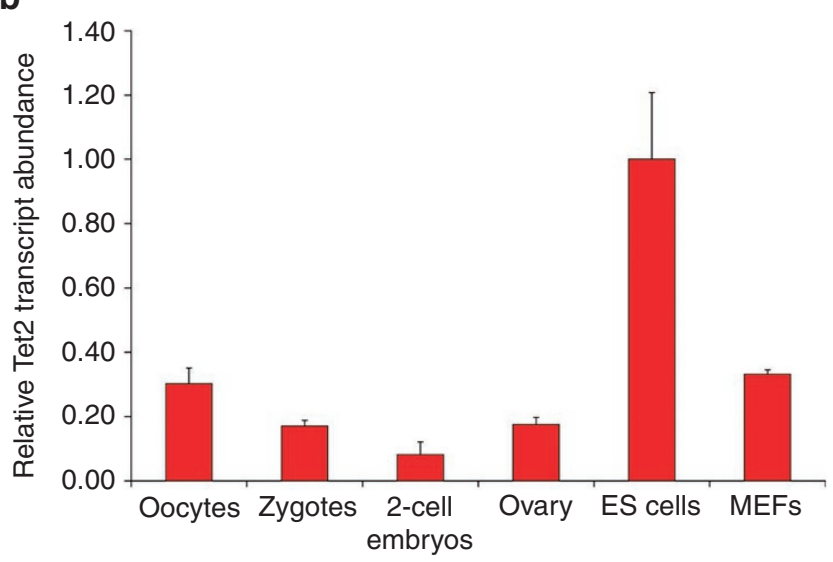

C

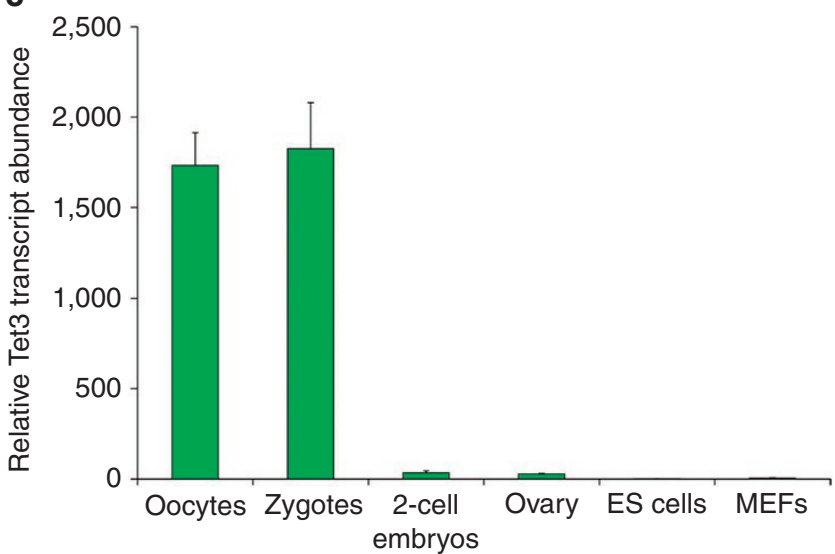

Figure 4 | Relative expression of Tet transcripts in development. Levels of Tet1 (a), Tet2 (b) and Tet3 (c) mRNA were measured by qRT-PCR. ES cells were used as calibrator sample (expression set to 1). The results are the average of three replicates with error bars (s.e.m.).

not continue in the 2-cell stage and the parental asymmetry of $5 \mathrm{hmC}$ appears to remain across the first cleavage. This indicates that $5 \mathrm{hmC}$ is a rather stable modification of early cleavage stages. It remains an open and very interesting question, how $5 \mathrm{hmC}$ affects the maintenance and de novo DNA methylation function of DNA methyltransferases. A second major finding of our work concerns the mechanisms of $5 \mathrm{hmC}$ generation. Our Tet 3 knockdown experiments show that $5 \mathrm{hmC}$ is apparently generated by a direct conversion of $5 \mathrm{mC}$ catalysed by this dioxygenase. Tet 3 is strongly expressed in oocytes and zygotes, but this expression significantly decreases in 2-cell embryos in line with the observation that we do not observe a further increase in $5 \mathrm{hmC}$ levels. The Tet knockdown effects in the zygote directly link the rapid active loss/demethylation of $5 \mathrm{mC}$ to its conversion into $5 \mathrm{hmC}$. Third, the conversion of $5 \mathrm{mC}$ to $5 \mathrm{hmC}$ by Tet 3 seems to be the dominant 'default' pathway in oocytes. Nuclei of cumulus cells transferred into enucleated oocytes (SCNT embryos) show a strong increase on their $5 \mathrm{hmC}$ content. Hence, the Tet-mediated conversion of $5 \mathrm{mC}$ to $5 \mathrm{hmC}$ is not a specific hallmark of decondensed sperm DNA alone. The question remains, what distinguishes paternal (and somatic) chromatin from the maternal genome as substrates for Tet3-mediated $5 \mathrm{mC}$ conversion. Our analysis shows that PGC7 has an important role in this process. In the maternal pronucleus, the Tet3-mediated oxidation is apparently blocked/inhibited by the presence of PGC7. In the absence of PGC7, the high $5 \mathrm{mC}$ content of the maternal genome can be converted into $5 \mathrm{hmC}$. How PGC7 exactly confers this protection remains unclear, but it seems likely that a particular chromatin composition of the maternal chromatin is required for this function.

How do the findings of an extensive loss of $5 \mathrm{mC}$ by conversion into $5 \mathrm{hmC}$ reconcile with previous results and interpretations on DNAdemethylation mechanisms ${ }^{7,21-23}$ ? Several lines of evidence suggested that base excision repair processes are associated with early prereplicative phases of DNA demethylation. Bisulphite analyses on early zygotic stages (PN1 to early PN3), however, only revealed a moderate decrease of modified cytosines ${ }^{7}$ (note that bisulphite sequencing does not distinguish between $5 \mathrm{mC}$ and $5 \mathrm{hmC}$ ). This indicates that a small but detectable fraction of $5 \mathrm{mC}$ is (directly) converted into cytosine by repair-coupled processes. It is tempting to speculate that the increased levels of $5 \mathrm{hmC}$ may well serve as an intermediate modification recognized by active, repair coupled demethylation processes either involving a deamination or a direct DNA glycosylase-induced repair? Indeed, mid to late stage paternal pronuclei, that is, pronuclei which contain extensive $5 \mathrm{hmC}$ and reduced $5 \mathrm{mC}$ levels show increased signatures of DNA strand breaks and repair markers ${ }^{7,23}$.

It is also conceivable that Tet enzymes or other oxygenases may catalyse a further enzymatic oxidation of the $5 \mathrm{hmC}$ intermediate, leading to decarboxylation reaction and finally a demethylated unmodified cytosine. However, our data suggest that $5 \mathrm{hmC}$ may not only serve as an intermediate modification that triggers active DNA-demethylation. The accumulation of $5 \mathrm{hmC}$ in the zygote and its persistence in the 2-cell stage point towards a relative stability of this modification. The generation of $5 \mathrm{hmC}$ may be linked to chromatin (re)organization events in early cleavage embryos, which mainly but not exclusively occurs in the paternal genome. On the molecular level, the conversion of $5 \mathrm{mC}$ into $5 \mathrm{hmC}$ is likely to interfere with the recognition and binding of $5 \mathrm{mC}$ recognizing proteins $\mathrm{s}^{24}$ (MBDs, NP95, Dnmt1 and so on) and, hence, directly or indirectly influence the transcriptional rate or DNA replication associated maintenance of DNA methylation. Recent data already point towards an important regulatory role of Tet1- and Tet2-mediated oxidation for ES cell development and maintenance of pluripotency ${ }^{14,25,26}$. A detailed molecular profiling of $5 \mathrm{hmC}$ during early cleavage stages and a genetic analysis of candidate modifiers such as Tet3 will certainly elucidate the biological functions of $5 \mathrm{hmC}$ for early development.

\section{Methods}

IVF of mouse oocytes. All animal experiments were carried out according to the German Animal Welfare law in agreement with the authorizing committee. Spermatozoa collection and IVF procedures were carried out as described ${ }^{27}$. Briefly, sperm was isolated from the cauda epididymis of adult F1(C57BL/6 $\times$ DBA) male mice and capacitated by pre-incubation for $1.5 \mathrm{~h}$ in pre-gassed modified KSOM medium (Millipore) supplemented with $30 \mathrm{mg} \mathrm{ml}^{-1}$ BSA. Mature oocytes were collected $14 \mathrm{~h}$ post-human chorionic gonadotropin (hCG) injection of adult $\mathrm{F} 1(\mathrm{C} 57 \mathrm{BL} / 6 \times \mathrm{DBA})$ female mice according to the standard procedures ${ }^{27}$. Cumulus-oocyte complexes (COCs) were placed into a $400 \mu \mathrm{l}$ drop of KSOM medium with capacitated sperm and incubated at $37^{\circ} \mathrm{C}$ in a humidified atmosphere of $5 \%$ $\mathrm{CO}_{2}$ and $95 \%$ air. Zygotes were collected at several time points corresponding to 
a

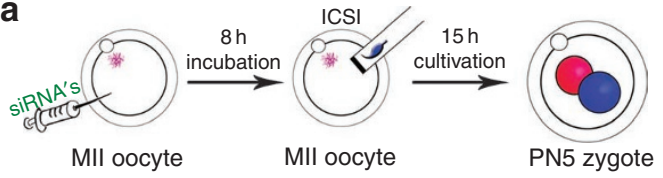

b
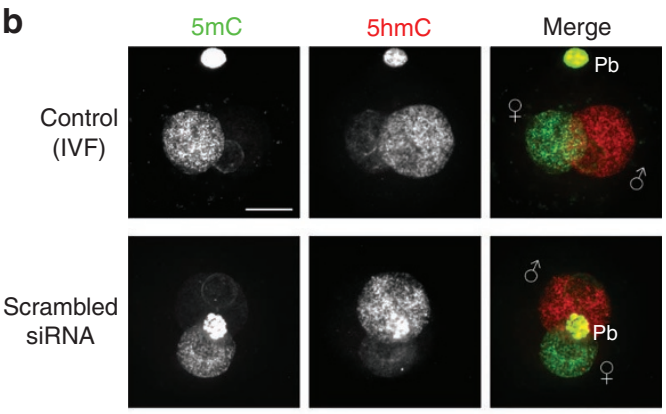

Tet1-3 KD
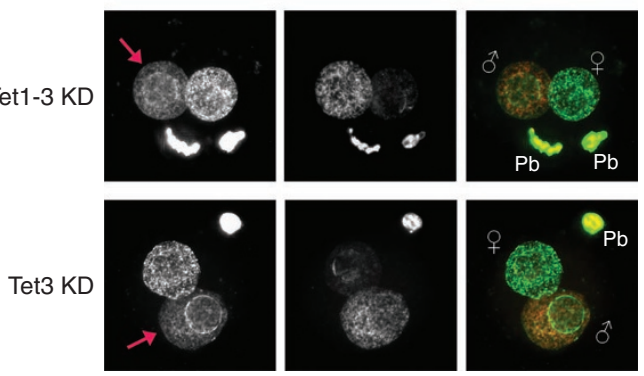
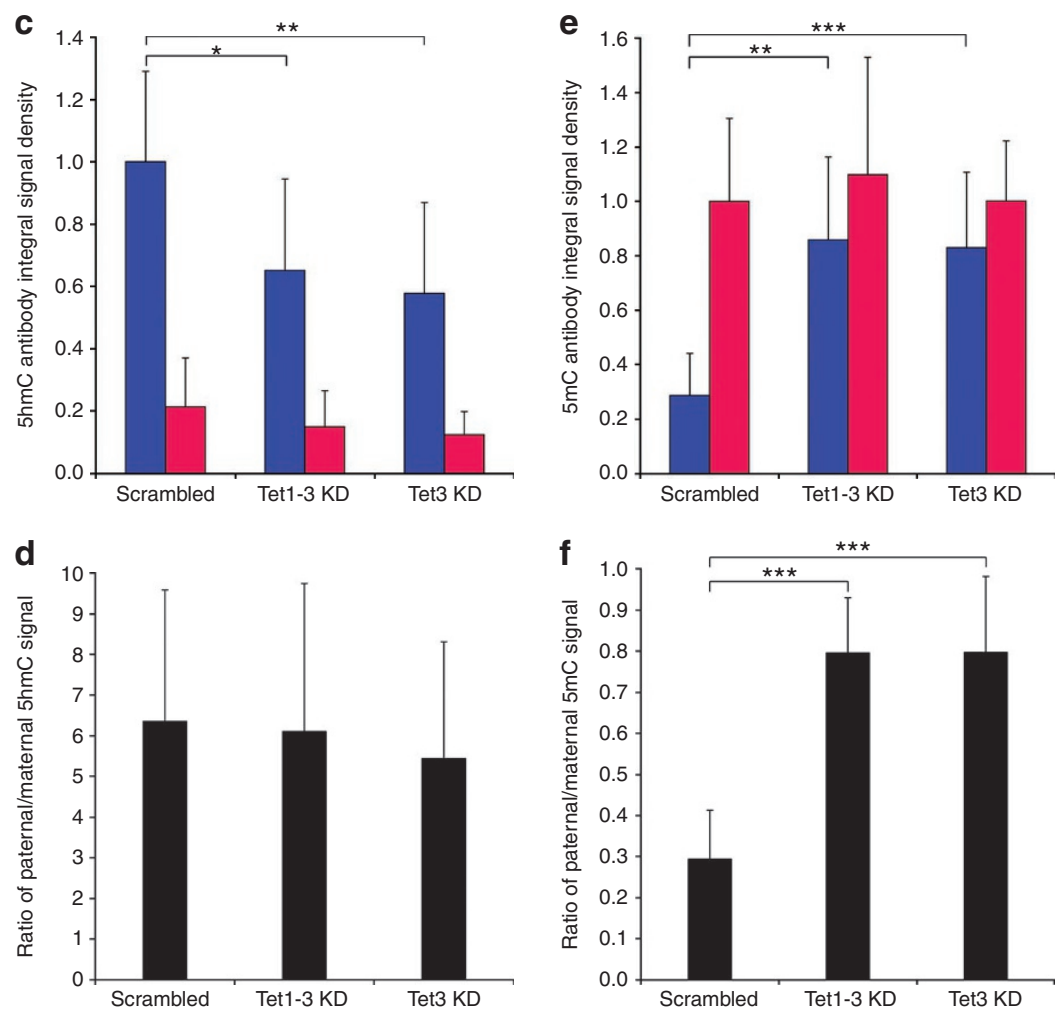

Figure $\mathbf{5}$ | Ablation of Tet proteins diminishes the loss of $\mathbf{5 m C}$ signal in the paternal genome of G2-phase zygotes. (a) Experimental setup according to Okada et al..$^{19}$. Briefly, siRNA injected metaphase II oocytes were cultured for $8 \mathrm{~h}$ and fertilized by intracytoplasmic sperm injection (ICSI). G2-phase zygotes were fixed and analysed for $5 \mathrm{mC}$ and $5 \mathrm{hmC}$ by immunofluorescence. (b) Representative images of $5 \mathrm{mC}$ (green mouse monoclonal, gift from Dirk Schübeler) and 5hmC (red rabbit polyclonal from Active Motif) immunostainings on G2-stage zygotes derived from Tet1-3 siRNA injected oocytes fertilized by ICSI. As control IVF-derived zygotes and zygotes derived from scrambled siRNA injected and ICSI fertilized oocytes are shown. Red arrows indicate the diminished loss of $5 \mathrm{mC}$ signal in paternal pronuclei of Tet KD-derived zygotes. Note the decreased $5 \mathrm{hmC}$ signal in Tet1-3 and Tet3 KDs. (c) Quantification of $5 \mathrm{hmC}$ signal of G2-phase zygotes derived from scrambled and Tet siRNA injected oocytes. (d) Paternal to maternal pronuclear $5 \mathrm{hmC}$ signal ratios. (e) Quantification of $5 \mathrm{mC}$ signal of $\mathrm{G} 2$-phase zygotes derived from scrambled and Tet siRNA injected oocytes. (f) Paternal to maternal pronuclear $5 \mathrm{mC}$ signal ratios. Blue bars represent signals from paternal pronuclei and red bars represent signals from maternal pronuclei. A total of 8-9 precisely staged ICSI-derived zygotes per group were analysed. Asterisks show significant changes of paternal or maternal $5 \mathrm{hmC} / 5 \mathrm{mC}$ signals calculated using Student's t-tests $\left(^{\star}=P<0.05,{ }^{\star \star}=P<0.01,{ }^{\star \star \star}=P<0.001\right)$. Error bars represent standard deviations. $\delta^{*}$, male pronucleus; + , female pronucleus; $\mathrm{Pb}$, polar body; scale bar, $20 \mu \mathrm{m}$.
$5 \mathrm{mC}$
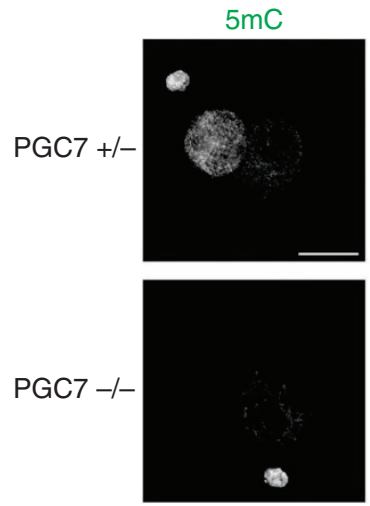

$5 \mathrm{hmC}$
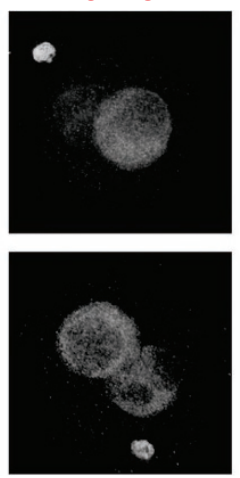

Merge
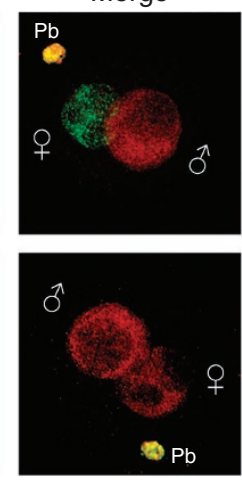

Figure 6 | Increase of $5 \mathrm{hmC}$ in the maternal genome of zygotes derived from PGC7-null oocytes. Representative images of G2-phase zygotes obtained from PGC7-null female mice stained with $5 \mathrm{mC}$ (green mouse monoclonal from calbiochem) and $5 \mathrm{hmC}$ (red rabbit polyclonal from Active Motif) antibodies $(N>20)$. $\hat{0}$, male pronucleus; 우, female pronucleus; $\mathrm{Pb}$, polar body; scale bar, $20 \mu \mathrm{m}$.

pronuclear stages from PN0 up to metaphase stage. The classification of PN stages was done according to Adenot et al. ${ }^{27}$ and Santos et al. ${ }^{6}$ in which the pronuclear morphology and hours post-fertilization are taken into consideration ${ }^{6,28}$. After brief washing in M2 medium, zona pellucida was removed by treatment with acidic tyrodes solution ${ }^{27}$. Subsequently, the zygotes were fixed for $20 \mathrm{~min}$ in $3.7 \%$ paraformaldehyde in PBS at $4{ }^{\circ} \mathrm{C}$ and permeabilized with $0.2 \%$ Triton $\mathrm{X}-100$ in PBS for $10 \mathrm{~min}$ at room temperature (RT). The fixed zygotes were blocked overnight at $4^{\circ} \mathrm{C}$ in $1 \%$ BSA, $0.1 \%$ Triton X-100 in PBS. For inhibition of DNA replication, IVF-derived zygotes were incubated with $3 \mu \mathrm{g} \mathrm{ml}^{-1}$ aphidicolin starting from 7 h.p.f. up to 14 h.p.f.

IVF of bovine oocytes. Bovine embryos were produced by in vitro maturation and fertilization of oocytes as previously described ${ }^{29}$. Briefly, cumulus-COCs were isolated from ovaries obtained from a local slaughterhouse. COCs were washed three times in culture medium TCM 199 (Seromed) supplemented with L-glutamine $\left(100 \mathrm{mgl}^{-1}\right), \mathrm{NaHCO}_{3}\left(3 \mathrm{gl}^{-1}\right)$, $\mathrm{HEPES}\left(1400 \mathrm{mgl}^{-1}\right)$, sodium pyruvate $\left(250 \mathrm{mgl}^{-1}\right)$, L-lactic-calcium salt $\left(600 \mathrm{mgl}^{-1}\right)$ and gentamicin $\left(55 \mathrm{mgl}^{-1}\right.$; Seromed). Oocytes were transferred to four-well plates (Nunc) with $400 \mathrm{ml} \mathrm{TCM}$ 199 supplemented with $10 \%$ oestrous cow serum and containing $0.2 \mathrm{U} \mathrm{ml}^{-1} \mathrm{o}-\mathrm{FSH}$ (Ovagen; ICPbio). Oocytes were matured for $20-22 \mathrm{~h}$ at $39^{\circ} \mathrm{C}$ in an atmosphere of $5 \% \mathrm{CO}_{2}$ and maximum humidity. Matured COCs were washed three times in fertilization medium (Tyrode albumin lactate pyruvate) supplemented with sodium pyruvate $\left(2.2 \mathrm{mg} \mathrm{ml}^{-1}\right)$, heparin sodium salt $\left(2 \mathrm{mg} \mathrm{ml}^{-1}\right)$, and BSA $\left(6 \mathrm{mg} \mathrm{ml}^{-1}\right)$ and transferred to $400-\mathrm{ml}$ droplets of medium. Frozen-thawed spermatozoa were subjected to the swim-up procedure for $90 \mathrm{~min}$. Then the COCs and spermatozoa $\left(2 \times 10^{6}\right.$ cells per $\left.\mathrm{ml}\right)$ were co-incubated for $18 \mathrm{~h}$ in maximum humidity, $39^{\circ} \mathrm{C}$ and $5 \% \mathrm{CO}_{2}$ in air. The presumptive zygotes were mechanically denuded by vortexing, washed three times in synthetic oviductal fluid culture medium enriched with $10 \%$ oestrous cow serum, BME $100 \times\left(20 \mathrm{ml} \mathrm{ml}^{-1}\right.$; Invitrogen) and MEM (minimum essential medium $) 100 \times\left(10 \mathrm{ml} \mathrm{ml}^{-1}\right.$, Invitrogen $)$ and transferred to $400-\mathrm{ml}$ droplets of medium covered with mineral oil (Sigma-Aldrich). The culture atmosphere was $5 \% \mathrm{CO}_{2}, 5 \% \mathrm{O}_{2}, 90 \% \mathrm{~N}_{2}$ and $39^{\circ} \mathrm{C}$ at maximum humidity. 
In vivo rabbit embryo production. Rabbit embryos were collected from superovulated outbred Zika rabbits mated with Zika males as described previously ${ }^{30}$. Briefly, female rabbits were superovulated by injection of 100 IU eCG (Intergonan; Intervet) intramuscularly and $100 \mathrm{IU}$ hCG (Ovogest 1500; Intervet) intravenously $72 \mathrm{~h}$ later and mated immediately after hCG injection. For recovery of zygotes, females were killed $16 \mathrm{~h}$ after mating and laparotomized. The oviducts were flushed and the fertilized oocytes transferred into 100-ml drops of MPM medium supplemented with $10 \%(\mathrm{v} / \mathrm{v})$ fetal calf serum (Biochrom), covered with mineral oil and cultured at $39^{\circ} \mathrm{C}$ in a humidified atmosphere of $5 \% \mathrm{CO}_{2}, 5 \% \mathrm{O}_{2}$ and $90 \% \mathrm{~N}_{2}$ (ref. 31). Embryos were cultured up to the G2-phase stage and fixed as described above.

Embryo staining and immunofluorescence microscopy. For the $5 \mathrm{hmC}$ and $5 \mathrm{mC}$ staining, fixed zygotes were incubated in $4 \mathrm{~N} \mathrm{HCl}$ solution at $\mathrm{RT}$ for $15 \mathrm{~min}$. Following neutralization ( $10 \mathrm{~min} 100 \mathrm{mM}$ Tris- $\mathrm{HCl}, \mathrm{pH} 8.0)$ and second fixation, the embryos were stained with anti-5hmC (two different antibodies, rabbit polyclonal from Active Motif (1/100) or rat monoclonal Ab 63.3 from W.R. and Adrian Bird $\left(20 \mu \mathrm{g} \mathrm{ml}^{-1}\right)$, available from Diagenode), anti-5mC (mouse monoclonal, gift from Dirk Schübeler $\left(0.2 \mu \mathrm{g} \mathrm{ml}^{-1}\right)$ and Calbiochem $\left.(1 / 2000)\right)$ and anti-ssDNA (mouse monoclonal from Millipore $\left(0.5 \mu \mathrm{g} \mathrm{ml}^{-1}\right)$ or rabbit polyclonal from Immuno-Biological Laboratories $\left.\left(0.5 \mu \mathrm{g} \mathrm{ml}^{-1}\right)\right)$. Followed by several washes in blocking solution the embryos were incubated at RT with anti-mouse or -rat secondary antibodies for $2 \mathrm{~h}$ coupled with Alexa Fluor $488\left(10 \mu \mathrm{g} \mathrm{ml}^{-1}\right)$ or $568\left(10 \mu \mathrm{g} \mathrm{ml}^{-1}\right.$; Molecular Probes) and anti-rabbit secondary antibodies coupled with Rhodamine Red-X (15 $\mu \mathrm{g} \mathrm{ml}^{-1}$, Jackson ImmunoResearch Laboratories). Zygotes were then washed and mounted on slides with a small drop of Vectashield (VectorLab) mounting medium. The embryos were analysed on Zeiss Axiovert 200M inverted microscope (Zeiss) as described ${ }^{7}$. Image J software was used to quantify antibody signals of Z-stack computed ( 20 stacks with $0.4 \mu \mathrm{m}$ per sample) IF images.

Somatic cell nuclear transfer. MII oocytes were collected from superovulated B6C3F1 mice, $14 \mathrm{~h}$ post-hCG administration. Oviducts were dissected in HEPESChatot, Ziomet, and Bavister (H-CZB) medium containing $50 \mathrm{IU} \mathrm{ml}^{-1}$ hyaluronidase for $20^{\prime}$; denuded MII oocytes were washed in $\alpha$-MEM, BSA $0.2 \%$ and cultured for $30^{\prime}$ in $\alpha-\mathrm{MEM}$ at $37^{\circ} \mathrm{C}$ in $5 \% \mathrm{CO}_{2}$. Enucleation was performed in $\mathrm{H}$-CZB containing $5 \mu \mathrm{g} \mathrm{ml}^{-1}$ cytochalasin B and $0.1 \%$ polyvinylpyrrolidon (PVP). Groups of 20 oocytes were enucleated in a time window of $10^{\prime}$ and then extensively washed and returned to the incubator in a drop of $\alpha$-MEM, $0.2 \%$ BSA. Nuclear transfer was done in $90 \%$ $\mathrm{H}-\mathrm{CZB}, 1 \%$ PVP. Reconstructed embryos were left to recover for at least $1 \mathrm{~h}$ in $\alpha$-MEM in the incubator before being chemically activated in $\mathrm{Ca}^{2+}$-free $\alpha$-MEM, $\mathrm{SrCl}_{2} 10 \mathrm{mM}$ in the presence of $5 \mu \mathrm{g} \mathrm{ml}^{-1}$ cytochalasin $\mathrm{B}$ and $0.05 \% \mathrm{DMSO}^{32}$. At different time points embryos were collected and fixed for further immunostaining.

Analysis of zygotes derived from PGC7-/- oocytes. PGC7 + / - and PGC7 - / female mice $>8$-weeks old were superovulated by injecting $5 \mathrm{U}$ of hCG $48 \mathrm{~h}$ after a $5 \mathrm{U}$ injection of pregnant mare serum gonadotropin and then mated with stud male mice. Zygotes were collected from the oviduct after $28 \mathrm{~h} \mathrm{hCG}$ injection and were analysed by immunostaining as described. The zygotes were mounted on slides with Mountant Permafluor (Lab Vision). IF was visualized using an LSM510 confocal laser scanning microscope (Carl Zeiss).

Expression analysis of Tet RNAs. Total RNA was isolated from mouse oocytes $(n=20, \mathrm{~B} 6 \times \mathrm{SD} 7)$, zygotes $(n=74, \mathrm{~B} 6 \times \mathrm{SD} 7)$, two-cell embryos $(n=33)$, ovary, ES cells (E14) and primary mouse embryonic fibroblasts (passage 3) using Trizol reagent (Invitrogen) supplemented with $60 \mu \mathrm{g}$ of mussel glycogen (Roche) for oocyte/embryo samples. cDNA was analysed by qRT-PCR using standard conditions. Ct values used for calculating relative expression were the average of three replicates and were normalized against two reference genes (Atp5b and $H s p 90 a b 1)$. The primers used are as follows: Atp5b F- $5^{\prime}$-ggccaagatgtcctgctgtt- $3^{\prime}$; Atp5b R-5' -gctggtagcctacagcagaagg- $3^{\prime}$; Hsp F-5'-gctggctgaggacaaggaga- $3^{\prime}$; Hsp R-5'-cgtcggttagtggaatcttcatg- $3^{\prime}$; Tet1 F- $5^{\prime}$-ccattctcacaaggacattcaca- $3^{\prime}$; Tet1 R- $5^{\prime}$-gcaggacgtggagttgttca- $3^{\prime}$; Tet $2 \mathrm{~F}-5^{\prime}$-gccattctcaggagtcactgc- $3^{\prime}$; Tet2 $\mathrm{R}-5^{\prime}$-acttctcgattgtcttctctattgagg- $3^{\prime} ;$ Tet $3 \mathrm{~F}-5^{\prime}$-ggtcacagcctgcatggact- $3^{\prime}$; Tet 3 $\mathrm{R}-5^{\prime}$-agcgattgtcttccttggtcag- $3^{\prime}$. Annealing temperatures of $58^{\circ} \mathrm{C}$ were used for all primer sets. Dissociation curves were performed to confirm specificity of the PCR products and relative expression was calculated with qBase software ${ }^{33}$.

Tet knockdown experiments. Experimental setup was done according to Okada et al..$^{19}$ siRNAs $(2 \mu \mathrm{M}$ each) were co-injected with Dextran-tetramethyl-rhodamine (Invitrogen, $3000 \mathrm{MW}, 100 \mu \mathrm{g} \mathrm{ml}^{-1}$ ) in MII arrested oocytes derived from superovulated $\mathrm{F} 1(\mathrm{C} 57 \mathrm{BL} / 6 \times \mathrm{DBA})$ mice. After $8 \mathrm{~h}$ of incubation at $37^{\circ} \mathrm{C}$ in a humidified atmosphere of 5\% CO2 and 95\% air, siRNA injected oocytes were fertilized by intracytoplasmic sperm injection. After $15 \mathrm{~h}$ of cultivation, G2-phase zygotes were fixed and analysed for $5 \mathrm{mC}$ and $5 \mathrm{hmC}$ by immunostaining as described. Quantification of $5 \mathrm{mC}$ and $5 \mathrm{hmC}$ signals was done as described. siRNA target sequences are listed in Supplementary Table S1.

\section{References}

1. Reik, W., Dean, W. \& Walter, J. Epigenetic reprogramming in mammalian development. Science 293, 1089-1093 (2001).
2. Sasaki, H. \& Matsui, Y. Epigenetic events in mammalian germ-cell development: reprogramming and beyond. Nat. Rev. Genet. 9, 129-140 (2008).

3. Surani, M. A., Hayashi, K. \& Hajkova, P. Genetic and epigenetic regulators of pluripotency. Cell 128, 747-762 (2007).

4. Mayer, W., Niveleau, A., Walter, J., Fundele, R. \& Haaf, T. Demethylation of the zygotic paternal genome. Nature 403, 501-502 (2000).

5. Dean, W. et al. Conservation of methylation reprogramming in mammalian development: aberrant reprogramming in cloned embryos. Proc. Natl Acad. Sci. USA 98, 13734-13738 (2001).

6. Santos, F., Hendrich, B., Reik, W. \& Dean, W. Dynamic reprogramming of DNA methylation in the early mouse embryo. Dev. Biol. 241, 172-182 (2002).

7. Wossidlo, M. et al. Dynamic link of DNA demethylation, DNA strand breaks and repair in mouse zygotes. Embo. J. 29, 1877-1888 (2010).

8. Gehring, M., Reik, W. \& Henikoff, S. DNA demethylation by DNA repair Trends Genet. 25, 82-90 (2009).

9. Wu, S. C. \& Zhang, Y. Active DNA demethylation: many roads lead to Rome. Nat. Rev. Mol. Cell Biol. 11, 607-620 (2010).

10. Sanz, L. A., Kota, S. K. \& Feil, R. Genome-wide DNA demethylation in mammals. Genome Biol. 11, 110 (2010)

11. Kriaucionis, S. \& Heintz, N. The nuclear DNA base 5-hydroxymethylcytosine is present in Purkinje neurons and the brain. Science 324, 929-930 (2009).

12. Tahiliani, M. et al. Conversion of 5-methylcytosine to 5-hydroxymethylcytosine in mammalian DNA by MLL partner TET1. Science 324, 930-935 (2009).

13. Huang, Y. et al. The behaviour of 5-hydroxymethylcytosine in bisulfite sequencing. PLoS One 5, e8888 (2010).

14. Ito, S. et al. Role of Tet proteins in $5 \mathrm{mC}$ to $5 \mathrm{hmC}$ conversion, ES-cell selfrenewal and inner cell mass specification. Nature 466, 1129-1133 (2010).

15. Sutherland, E., Coe, L. \& Raleigh, E. A. McrBC: a multisubunit GTP-dependent restriction endonuclease. J. Mol. Biol. 225, 327-348 (1992).

16. Koji, T., Kondo, S., Hishikawa, Y., An, S. \& Sato, Y. In situ detection of methylated DNA by histo endonuclease-linked detection of methylated DNA sites: a new principle of analysis of DNA methylation. Histochem. Cell Biol. 130, 917-925 (2008).

17. Lepikhov, K. et al. Evidence for conserved DNA and histone H3 methylation reprogramming in mouse, bovine and rabbit zygotes. Epigenetics Chromatin 1, 8 (2008)

18. Liutkeviciute, Z., Lukinavicius, G., Masevicius, V., Daujotyte, D. \& Klimasauskas, S. Cytosine-5-methyltransferases add aldehydes to DNA. Nat. Chem. Biol. 5, 400-402 (2009).

19. Okada, Y., Yamagata, K., Hong, K., Wakayama, T. \& Zhang, Y. A role for the elongator complex in zygotic paternal genome demethylation. Nature 463, 554-558 (2010).

20. Nakamura, T. et al. PGC7/Stella protects against DNA demethylation in early embryogenesis. Nat. Cell Biol. 9, 64-71 (2007).

21. Oswald, J. et al. Active demethylation of the paternal genome in the mouse zygote. Curr. Biol. 10, 475-478 (2000).

22. Lane, N. et al. Resistance of IAPs to methylation reprogramming may provide mechanism for epigenetic inheritance in the mouse. Genesis 35, 88-93 (2003).

23. Hajkova, P. et al. Genome-wide reprogramming in the mouse germ line entails the base excision repair pathway. Science 329, 78-82 (2010).

24. Valinluck, V. et al. Oxidative damage to methyl-CpG sequences inhibits the binding of the methyl-CpG binding domain (MBD) of methyl-CpG binding protein 2 (MeCP2). Nucleic. Acids Res. 32, 4100-4108 (2004).

25. Walter, J. An Epigenetic Tet a Tet with Pluripotency. Cell Stem Cell 8, 121-122 (2011).

26. Koh, K. P. et al. Tet 1 and Tet 2 Regulate 5-Hydroxymethylcytosine production and cell lineage specification in mouse embryonic stem cells. Cell Stem Cell $\mathbf{8}$, 200-213 (2011)

27. Nagy, A. Manipulating the Mouse Embryo: A Laboratory Manual (Cold Spring Harbor Laboratory Press, 2003)

28. Adenot, P. G., Mercier, Y., Renard, J. P. \& Thompson, E. M. Differential H4 acetylation of paternal and maternal chromatin precedes DNA replication and differential transcriptional activity in pronuclei of 1-cell mouse embryos. Development 124, 4615-4625 (1997).

29. Hiendleder, S. et al. Tissue-specific elevated genomic cytosine methylation levels are associated with an overgrowth phenotype of bovine fetuses derived by in vitro techniques. Biol. Reprod. 71, 217-223 (2004)

30. Shi, W., Dirim, F., Wolf, E., Zakhartchenko, V. \& Haaf, T. Methylation reprogramming and chromosomal aneuploidy in in vivo fertilized and cloned rabbit preimplantation embryos. Biol. Reprod. 71, 340-347 (2004).

31. Galat, V., Lagutina, I., Mezina, M., Prokofiev, M. I. \& Zakhartchenko, V. Effect of donor cell age on the efficiency of nuclear transfer in rabbits. Reprod. Biomed. Online 4, 32-37 (2002).

32. Boiani, M., Eckardt, S., Scholer, H. R. \& McLaughlin, K. J. Oct4 distribution and level in mouse clones: consequences for pluripotency. Genes Dev. 16, 1209-1219 (2002).

33. Hellemans, J., Mortier, G., De Paepe, A., Speleman, F. \& Vandesompele, J. qBase relative quantification framework and software for management and automated analysis of real-time quantitative PCR data. Genome Biol. 8, R19 (2007). 


\section{Acknowledgments}

We would like to thank Dirk Schübeler for the $5 \mathrm{mC}$ antibodies, Adrian. Bird and A. Rao for $5 \mathrm{hmC}$ antibodies, and Fatima Santos, Wendy Dean and Gabriella Ficz for help and advice. This work was supported by a grant from Deutsche Forschungsgemeinschaft (DFG) WA 1029/4-1, EMBO long-term fellowship (ALTF 1007-2009), by the EPIGENOME Network of Excellence LSHG-CT-2004-503433, and by the Biotechnology and Biological Sciences Research Council and the Medical Research Council.

\section{Author contributions}

J.W., W.R. and T. Nakano conceived the project and wrote (with M.W.) the manuscript. M.W, T. Nakamura, K.L., C.J.M. designed, performed the experiments and evaluated the results. V.Z. provided rabbit and bovine zygotes and M.B. provided cloned one-cell embryos. J.A. evaluated results and performed statistical analysis.

\section{Additional information}

Supplementary Information accompanies this paper at http://www.nature.com/ naturecommunications

Competing financial interests: The authors declare no competing financial interests.

Reprints and permission information is available online at http://npg.nature.com/ reprintsandpermissions/

How to cite this article: Wossidlo, M. et al. 5-Hydroxymethylcytosine in the mammalian zygote is linked with epigenetic reprogramming. Nat. Commun. 2:241 doi: $10.1038 /$ ncomms1240 (2011) 